\title{
Ядерная безопасность в Юго-Восточной Азии: вызовы и направления сотрудничества
}

\section{Введение}

Обеспечение ядерной безопасности остается глобальной проблемой. Помимо государств, обладающих ядерным оружием и атомными электростанциями (АЭС), в зону риска попадают страны, использующие возможности "мирного атома" и обладающие радиоактивными материалами, а также соседи ядерных государств. Согласно определению Международного агентства по атомной энергии (МАГАТЭ), ядерная безопасность (ЯБ) это "предотвращение, обнаружение и реагирование на кражу, саботаж, несанкционированный доступ, незаконную передачу или другие злонамеренные действия, связанные с ядерным материалом, другими радиоактивными веществами или связанными с ними объектами" [19, р. 3].

В нач. XXI в., когда начали пересматриваться концепция безопасности АЭС и дальнейшее развитие "культуры ядерной безопасности" как одной из основ атомной энергетики, определяющим моментом в данном процессе стал афоризм бывшего главы МАГАТЭ Ханса Бликса о том, что "ядерная авария где-то является аварией везде" [17, p. 243]. Несмотря на то, что в мире, в том числе благодаря проводимым МАГАТЭ мероприятиям [26], существенно возросла осведомленность о проблемах распространения ядерных материалов, обеспечения фрункционирования АЭС, сохранности ядерных объектов, вопросы управления ЯБ на глобальном и региональном уровнях до сих пор сохраняют остроту. В этом отношении внимание исследователей и экспертов уделяется ситуации в Юго-Восточной Азии (ЮВА), где на протяжении нескольких десятилетий изучаются вопросы о включении ядерных технологий в социально-экономическую сфреру и разрабатываются программы развития ядерной энергетики. Проблема нуклеаризации ЮВА находится в фоокусе внимания как отечественных (И. Ахтамзян, В. Мурогов, А. Колбин, Н. Кутнаева, С. Ключанская, А. Чебан), так и зарубежных (Р. Финч, Д. Эммерт, Д. Олбрайт, Х.С. Трахано, К.-А. Мели, П. Н. Аджа) исследователей, которые помимо деталей развития ядерной энергетики и ядерных технологий в ЮВА также затрагивают сопутствующие этим процессам вопросы безопасности.

\section{Угрозы ядерной безопасности в Юго-Восточной Азии}

Бурный экономический рост в странах ЮВА, сопряженный с увеличением масштабов энергопотребления, поставил перед руководством членов ACEAН варианты решения вопроса обеспечения эффеективного энергоснабжения, среди которых фигурировало развитие "мирного атома". В то же время реализация национальных программ развития атомной энергетики оказалась неразрывно связана с необходимостью решения проблем безопасности, усугубляемых рисками, связанными с использованием ядерных технологий [3, c. 71].

(C) Золотухин И. Н., Бобыло А. М., 2020

ЗОЛОТУХИн Иван Николаевич, канд. полит. наук, доцент кафедры международных отношений Дальневосточного федерального университета (2. Владивосток). E-mail: zolivnik@mail.ru

БОБЫЛо Андрей Михайлович, канд. полит. наук, начальник Управления экспорта образования Национального исследовательского ядерного университета "МИФИ" (г. Москва). E-mail: sibiryak_84@mail.ru 
Вероятность "ядерного ренессанса"1 заставляет страны ЮВА уделять внимание угрозам, обусловленным природными, социальными, геополитическими фракторами. Среди ключевых вызовов для ядерной безопасности ЮВА можно выделить риски чрезвычайных ситуаций, высокий уровень террористической активности, проблемы пиратства, политические разногласия, недостаточный пограничный и әкспортный контроль, дефицит квалифицированных специалистов в ядерной сфере, риски и угрозы кибербезопасности, возможность использования отработанных ядерных материалов в военных целях.

Природные катаклизмы являются "визитной карточкой" региона. К наиболее распространённым стихийным бедствиям в ЮВА относятся землетрясения, тропические циклоны, речные наводнения и цунами [27, p. 2]. Возрастает число геофизических катастроф. Расположение стран ЮВА в сейсмоопасном поясе по умолчанию создает риски геофизических катастрофр, число которых возрастает. Например, в 2016 г. число зарегистрированных стихийных бедствий в Индонезии на 83,9\% превысило показатели 2015 г. [25, p. 145] Самыми разрушительными катаклизмами в ЮВА в XXI в. стали цунами в Индийском океане в 2004 г., землетрясения в Паданге в 2006, в Джокьякарте в 2009, на Сулавеси в 2018 г., циклон Наргис в 2008 г., тайфун Хайян в 2013 г. Еще одним фактором, создающим риски перспективам мирной нуклеаризации ЮВА, становится колоссальное давление со стороны стран региона на окружающую среду. В результате активизация хозяйственной деятельности, ориентированной на повышение прибыли и материального благосостояния, привела к обострению экологической ситуации.

Опасность природных и экологических катастроф создает обеспокоенность как среди руководства стран ЮВА, так и международного сообщества по поводу радиоактивных утечек или аварий, которые могут нанести серьезный ущерб окружающей среде. Это касается как возможного использования плавучих ядерных реакторов, так и наземных АЭС. Ситуащия усугубляется тесным соседством государств ЮВА друг с другом, из-за чего риск ядерного заражения приобретает трансграничный характер и становится еще опаснее. Несмотря на то, что в настоящее время в ЮВА нет действующих атомных станций, недалеко от Вьетнама расположены три китайские, а Бангладеш начал в 2017 г. совместно с Россией строительство своей первой АЭС всего в 500 км от границы с Мьянмой [13].

Негативными фокторами, препятствующими созданию ядерного сектора в ЮВА, являются политическая нестабильность и опасность терактов, особенно в свете активизации террористического интернационала на Филиппинах, в Индонезии, Таиланде, а также сложной внутриполитической обстановки в Мьянме. Хотя до настоящего момента регион не сталкивался с актами ядерного терроризма, нельзя исключать возможности доступа террористических группировок к радиоактивным материалам с плохо охраняемых ядерных объектов.

Серьезную угрозу обеспечения фрнкционирования плавучих реакторов представляют проблемы безопасности на море, такие как пиратство (особенно связь пиратства и терроризма), нарушения в обеспечении морских перевозок, контрабанда запрещенных материалов, территориальные споры.

Наличие политических и экономических противоречий между государствами ЮВА также не способствует улучшению атмосферы доверительных отношений, важных для развития ядерных технологий в регионе. Не менее серьезным препятствием на пути бесконфликтного взаимодействия являются сохраняющиеся трения в отношениях между региональными и внерегиональными игроками. В этом смысле показательна напряженная ситуация в Южно-Китайском море, где Китай усиливает свое присутствие и готов разместить плавучие АЭС (ПАТЭС). С другой стороны, не следует исключать вероятности

1 Ядерный ренессанс ("ренессанс атомной энергетики") - возрождение интереса к развитию ядерной энергетики на глобальном уровне в начале XXI в. [21] после 15-тилетнего периода застоя, вызванного катастрофой на Чернобыльской АЭС. Примечательно, что после аварии на Фукусиме большинство стран ЮВА не отказалось от намерений развивать программы "мирного атома", хотя в дальнейшем скорректировали сроки вероятного запуска АЭС на более отдаленную перспективу. 
того, что развитие "мирного атома" в ЮВА поможет хотя бы частично снизить накал противоречий вокруг спорных территорий, особенно шельфовой зоны, обладающей залежами нефти и газа.

Вопрос морской безопасности связан с рисками перевозки радиоактивных материалов. Большинство стран ЮВА обладают протяженной береговой линией (особенно архипелажные Филиппины и Индонезия), что затрудняет таможенный контроль над перемещением товаров, особенно учитывая недостаточность системы наблюдения и мониторинга в портах. Развитие странами ЮВА атомной энергетики откроет поставки на их территорию ядерного топлива для АЭС, что соответствует положениям режима нераспространения ядерного оружия (РНЯО), однако параллельно возникает проблема утилизации и вывоза облученного ядерного топлива (ОЯТ). Очевидно, что незащищенные морские перевозки, также как сохранение ОЯТ на территории стран ЮВА в условиях рисков природных и социальных катаклизмов, могут привести к катастрофическим последствиям. Теневой стороной сохранения ОЯТ является потенциальная возможность для стран ЮВА извлекать содержащийся в нём плутоний для использования в разработке ядерного оружия.

Серьезным вызовом для обеспечения ЯБ в ЮВА является отсутствие в странах региона совершенной системы экспортного контроля, что создает возможность для нелегального транзита ядерных и радиоактивных материалов. Например, в 2003 г. в Таиланде была раскрыта сеть контрабандистов, пытавшихся продать переправляемый через Лаос высокотоксичный цезий-137 [7, с. 68]. В период с 2013 по 2018 гг. в ЮВА произошло пять случаев пропажи, незаконного оборота или хищения радиоактивных материалов [14]. Трудности осуществления әкспортного контроля в странах ЮВА связаны с их быстрым экономическим ростом, из-за которого возникли сложности в проведении проверки экспортируемой и импортируемой продукции по причине недостаточного количества оборудования. Большинство таможен стран Индокитая не оснащено компьютерами, не говоря о радиационных мониторах [7, c. 69].

Помимо технических моментов, ядерные проблемы в ЮВА обусловлены отсутствием квалифицированных специалистов в области фризической защиты ядерных объектов (условно, "техников" и "гуманитариев": первые, обладая надлежащей технической подготовкой, должны поддерживать фрункционирование и защиту ядерных объектов, а также препятствовать нелегальному трафику ядерных материалов; вторые, будучи гуманитарными специалистами, должны влиять на совершенствование национального законодательства и выработку культуры физической ядерной безопасности $\left.(\text { ФББ })^{2}\right)$.

Слабая культура ФЯБ в странах ЮВА является очевидным пробелом, из-за которого возможны аварийные ситуации, хищения и просто непонимание ситуации вокруг ядерного фрактора. Не все страны ЮВА присоединились к базовым международным документам в области нераспространения и ФЯБ (дополнительному протоколу к соглашению о гарантиях с МАГАТЭ, конвенции о физической защите ядерных материалов, международной конвенции о борьбе с актами ядерного терроризма). Только Индонезии удалось разработать политико-правовые рамки внедрения культуры ФЯБ. Индонезия признана МАГАТЭ первой страной в мире, которая, руководствуясь с руководящими принципами Агентства, провела независимую оценку культуры безопасности по ядерным реакторам и другим исследовательским установкам, связанным с ядерными и радиоактивными материалами [24].

C развитием передовой технологической инфраструктуры серьезной проблемой для функционирования ядерных объектов могут стать кибератаки, особенно со стороны радикальных антиправительственных группировок. В связи с этим странам ЮВА предстоит усовершенствовать национальные системы кибербезопасности, в том числе благодаря сотрудничеству с зарубежными партнерами по программам в области информационной безопасности и заимствованию их опыта в противодействии киберугрозам.

2 Под культурой физической ядерной безопасности подразумевается "совокупность характеристик, установок и поведения отдельных лиц, организаций и учреждений, которая служит средством поддержкии и укрепления физической ядерной безопасности" [11, p.20]. 
Наличие в странах ЮВА ядерных объектов (исследовательские реакторы, радиоактивные источники, замороженная Батаанская АЭС на Филиппинах) и увеличение в них потока ядерных материалов требуют обеспечения ФЯБ. Проявляя интерес к развитию ядерных технологий, страны ЮВА стоят перед необходимостью предотвращения рисков, связанных с их использованием, что ставит перед странами задачу укрепления регионального потенциала многостороннего сотрудничества, направленного на решение вопросов в сфрере ЯБ.

\section{Региональные инструменты укрепления ядерной безопасности в Юго-Восточной Азии}

Региональное сотрудничество играет важную роль в развитии международных отношений в ЮВА, где Ассоциация государств Юго-Восточной Азии (ACEAH) выступает в качестве успешного интеграционного проекта и ключевого әлемента архитектуры безопасности. В рамках ACEAH выработано несколько региональных инструментов, касающихся как внедрения, так и усиления программ физической защиты радиоактивных материалов, в частности Бангкокский договор о Зоне свободной от ядерного оружия, региональный проект МАГАТЭ "Программа технического сотрудничества", Форум ядерного сотрудничества в Азии и др. В ЮВА получила распространение сеть ядерной судебной экспертизы. Страны региона (Бруней, Камбоджа, Сингапур, Таиланд, Филиппины) участвуют в "Инициативе по безопасности в борьбе с распространением оружия массового уничтожения, ИБОР-ОМУ". Сингапур с 2005 г. проводит морские учения (Deep Sabre) по недопущению судов, провозящих ОМУ и технологии их создания [15]. С сентября 2013 г. запущен формат международных встреч в рамках ACEAHTOM (АСЕАНовской сети регулирующих органов по атомной энергии), в который помимо стран ЮВА вошли члены МАГАТЭ. АСЕАНТОМ нацелен на развитие сотрудничества в сфере ЯБ, проведение ядерной экспертизы, предотвращение незаконной перевозки ядерных и радиоактивных материалов и возвращение использованных радиоактивных материалов в страны происхождения [15]. Пять государств АСЕАН являются членами АНЕНТ (Азиатской сети образования в области ядерных технологий), которая занимается распространением, управлением и укреплением знаний в ядерной сфере, а также обеспечением постоянной доступности талантливых и квалифицированных кадров к отрасли ядерных исследований в Азии и улучшением ресурсов для устойчивого развития ядерных технологий [18, p. 104].

В ноябре 2018 г. на XIII Восточноазиатском саммите (BAC) было принято первое совместное заявление лидеров стран Восточной Азии о безопасном и охраняемом использовании, хранении и транспортировании ядерных и радиоактивных материалов. Безопасность и защита ядерных и радиологических материалов провозглашается региональной проблемой в ATP, a ACEAHTOM оказалась единственной региональной сетью, упомянутой в совместном заявлении и получившей признание со стороны членов ВАС за свою работу [16, p. 2]. Заявление призвало все государства поддерживать и улучшать свою инфраструктуру ФЯБ, а также оказывать помощь и содействовать международному обмену опытом, знаниями и передовой практикой $[\mathbf{1 6}, \mathbf{p .} 2]$.

Ядерная безопасность является ключевой региональной повесткой дня, установленной АСЕАНТОМ с учетом необходимости повышения осведомленности среди государственных и негосударственных субъектов о важности управления ФЯБ в ЮВА. В рамках программы обмена знаниями АCEAHTOM осуществляет адресную помощь странам, испытывающим недостаток знаний и опыта. Например, Камбоджа и Лаос не имеют достаточно хорошо обученного персонала и регулирующей инфраструктуры, особенно для регулирования радиоактивных материалов, и с 2017 г. Таиланд, обладающий более широкими знаниями в ядерной области, помогает своим соседям в сфере регулирования ядерной деятельности и онлайн-мониторинга радиации в окружающей среде посредством проведения семинаров по техническому сотрудничеству $[16$, p. 6].

Также АСЕАНТОМ оказывает поддержку созданию в ЮВА центров передового опыта и знаний для подготовки квалифицированных кадров в обла- 
сти эфофективного надзора за ядерными и радиоактивными материалами и обеспечения надежного режима ФЯБ внутри государства. Еще одним направлением деятельности АСЕАНТОМ является реализация проектов по предотвращению аварийных ситуаций и реагированию на них. Недавно АCEAHTOM разработал с Координационным центром АСЕАН по оказанию гуманитарной помощи в области борьбы со стихийными бедствиями протокол по ядерным и радиационным авариям [9]. В сотрудничестве с МАГАТЭ АСЕАНТОМ запустил в 2016 г. региональный проект по поддержке готовности к ядерным авариям и реагированию на них, который был направлен для создания базы данных АCЕАН для оказания технической помощи государствам-членам по оперативному реагированию на аварийные ситуации на ядерных объектах [10]. Сотрудничество в данной сфере ведется и с ЕС.

Другим ключевым органом в области ФЯБ является Региональное партнерство по радиологической безопасности, инициированное Австралией в 2004 г. совместно с МАГАТЭ и ориентированное на улучшение управления физической защитой и безопасностью радиоактивных источников высокого риска в ЮВА посредством технической подготовки и помощи, предоставления устройств обнаружения радиации, обмена передовым опытом и содействия совместным усилиям по поиску пропавших без вести [11].

Однако, несмотря на заметный прогресс в укреплении сотрудничества в области ФЯБ в ЮВА и потенциал для создания и расширения региональных механизмов, на повестке дня остается вопрос участия членов АСЕАН в глобальных конвенциях по ядерной безопасности. Важность коллективного присоединения к конвенции о физической защите ядерного материала и ее поправке неоднократно подчеркивал АСЕАНТОМ. Поправка расширяет сфреру действия КФЗЯМ и включает требования фризической защиты для ядерных установок и ядерных материалов при использовании, хранении и транспортировке внутри страны, кроме того, она криминализирует ядерную контрабанду, торговлю и саботаж и предусматривает расширение сотрудничества между странами по обнаружению и возвращению украденного или контрабандного ядерного материала [6].

Поскольку риски для фризической защиты ядерных установок и материалов, такие как кража радиоактивных материалов и ядерный терроризм, чреваты катастрофическими региональными последствиями, в идеале странам ACEAH, запустившим или запускающим ядерные программы, важно ратифицировать все договоры и осуществлять даже юридически необязательные руководящие принципы МАГАТЭ, способствуя тем самым укреплению архитектуры региональной ЯБ.

В то же время региональные эксперты указали на необходимость оказания международной помощи странам ЮВА в разработке и обновлении соответствующих законодательных и нормативных актов, связанных с планами реализации программ по обеспечению ФЯБ. Укреплению или созданию инфраструктуры ФЯБ может помочь содействие со стороны государств, обладающих развитыми ядерными технологиями, среди которых фригурируют США, страны Евросоюза, Япония, Канада, Россия [22, р. 64]. Страны ЮВА перед лицом новых угроз и вызовов в области международной безопасности, включая растущее технологическое соперничество между государствами, обладающими ядерным оружием, ожидают от внешних игроков усилий и гарантий по укреплению безопасности в регионе в рамках режима нераспространения ядерного оружия.

\section{Проблемы формирования безъядерной зоны в Юго-Восточной Азии}

За более чем полувековой период своего существования АCЕАН показала умение принимать коллективные решения, направленные на недопущение в регионе военных конфликтов. Конструктивный опыт АСЕАН в сглаживании региональных противоречий, с опорой на разветвленные институты, неофициальные переговорные каналы, структуры "полуторной" и "второй" дорожек дипломатии, помог организации заслужить кредит доверия со стороны внерегиональных партнёров.

В то же время успех ACEAН в создании новых региональных институтов не снимает с повестки дня вопрос их әфффективности, особенно когда дело 
касается "острых углов" проблем безопасности. В этом смысле показательна ситуация с созданием в ЮВА зоны свободной от ядерного оружия (ЗСЯО) или безъядерной зоны [5, с. 75]. ЗСЯО являются важным инструментом обеспечения режима нераспространения ядерного оружия и технологий двойного назначения. Действуя на основе международных многосторонних договоров, они исключают применение ядерного оружия на определенной территории и, согласно Резолюции Генеральной Ассамблеи ООН № 3472В, принятой в 1975 г., являются одним из наиболее эффрективных средств предотвращения как горизонтального, так и вертикального распространения ядерного оружия ${ }^{3}$ и содействия устранению опасности ядерной катастрофы [20].

Первые безъядерные зоны возникают до появления Договора о нераспространении ядерного оружия (ДНЯО) ${ }^{4}$, но в дальнейшем они стали инструментом его поддержки. На сегодняшний момент создано $53^{3} \mathrm{CЯO}^{5}$, четыре из которых охватывают все южное полушарие. Безъядерные зоны обязуются не создавать, не приобретать, не испытывать, не обладать ЯО. В них неприемлемо развертывание ЯО, принадлежащего ядерным государствам, что в ДНЯО не запрещено. ЗСЯО должна быть обязательно признана Генассамблеей $\mathrm{OOH}$, закреплена в международном договоре и снабжена механизмом верификации, обязана иметь четко определённые делимитированные границы, a её участники должны принять на себя безоговорочные обязательства о недопущении нахождения ядерного оружия в зоне действия соответствующего договора [2].

Дискуссии о создании в ЮВА безъядерной зоны начались после вскоре после того как политические элиты АCEAН в 1971 г. подписали Декларацию о создании зоны мира, свободы и нейтралитета (Zone of Peace, Freedom and Neutrality, ZOPFAN [30]), однако реальный результат переговоров региональных лидеров нашел свое воплощение через 24 года, когда сторонам удалось достичь консенсуса касательно условий соглашения. Договор о ЗСЯО в ЮВА был подписан в 1995 г. в Бангкоке и вступил в силу в марте 1997 г. В настоящий момент его ратифицировали все 10 членов АСЕАН [28].

Бангкокский договор 1995 г. носит бессрочный характер и его условия охватывают широкий диапазон мер, начиная от запрета разработки, производства, приобретения ЯО и захоронения радиоактивных веществ любым способом на своей территории, заканчивая соблюдением обязательств государств-участников заключить с МАГАТЭ соглашение о гарантиях. Кроме того, в договоре оговорено, что на усмотрение подписантов остается транзит иностранных кораблей и самолетов в иных, кроме мирного прохода, целях [28].

Верификационный механизм договора должен обеспечиваться через регулярные отчеты и обмен информацией между подписантами, а также через применение гарантий МАГАТЭ. При этом в соглашении не содержится положения об инспекциях по запросу, а имеются нечеткие формулировки о миссиях по установлению фрактов. Каждый участник договора вправе потребовать отправки подобной миссии в другое государство с целью прояснения и разрешения сомнений относительно его соблюдения. Также в рамках договора была учреждена комиссия по вопросам ЗСЯО в ЮВА, в задачи которой входит наблюдение за реализацией договора и обеспечение его соблюдения $[4$, c. 86].

При разработке положений Бангкокского договора учитывался имеющийся международный опыт, причем создатели соглашения попытались его

3 Горизонтальное распространение ядерного оружия - это его передача от ядерного государства к неядерному; вертикальное распространение ядерного оружия это количественное и качественное (разрушительная мощь) увеличение ядерного оружия в ядерном государстве [5, c.77].

4 Например, договор об Антарктике (1959 г.) и Договор Тлателолко о запрете ядерного оружия в Латинской Америке и странах Карибского бассейна (1967 г.).

5 В настоящее время существуют ЗСЯО в следующих регионах: Латинская Америка (Договор Тлателолко, 1967 г.), Южно-Тихоокеанский регион (Договор Раротонга, 1985 г.), Юго-Восточная Азия (Бангкокский договор, 1995 г.), Афррика (Пелиндабский договор, 1996 г.) и Центральная Азия (Семипалатинский договор, 2006 г.) 
усовершенствовать. Договор включает территорию, территориальные воды, 200-мильную исключительную экономическую зону (ИЭЗ) и континентальный шельф каждого государства-участника договора, что объясняется желанием подписантов обезопасить себя от вредных экологических последствий в случае возможного ядерного конфликта. Кроме того, в протоколе к договору говорится, что официальные ядерные государства (ЯОГ) - Россия, США, КНР, Великобритания, Франция - берут на себя обязательства не применять и не угрожать применением ядерного оружия не только странам - участницам договора, но и внутри безъядерной зоны в целом [23].

Однако усовершенствования положений Договора о зоне предопределили дальнейшие проблемы с подписанием протокола, который до сих пор не ратифицировала ни одна из пяти ЯОГ. Главной причиной этого являются разногласия в определении территориальных рамок региона. Включение континентального шельфа и ИЭЗ в ЗСЯО делает ее границы слишком широкими и нечеткими. Китайская сторона возражает против территориальной сферы действия договора, в который включены районы Южно-Китайского моря, являющиеся предметом спора между Китаем и рядом стран ЮВА. Франция и Великобритания возражают против положений договора, касающихся континентального шельфа и ИЭЗ, поскольку они нарушают Конвенцию ООН по морскому праву, разрешающую прибрежным государствам разрабатывать полезные ископаемые в пределах ИЭЗ и на континентальном шельфе, но не дающую им право осуществлять над ними политический контроль. Кроме того, страны ядерной пятерки (прежде всего США, Россия и КНР) не были готовы согласиться с тем, что договор предоставляет странам-участницам слишком широкие права в отношении территории, входящей в зону, из-за чего могут возникнуть угрозы способности ЯОГ перемещать в регионе свои военные корабли и подводные лодки [3, с. 87]. По мнению Ахтамзяна, специфика экономического развития государств ЮВА опередила развитие правовых механизмов, закрепляющих основы безопасности [1].

Неготовность ЯОГ подписать протокол, дающий странам-участницам негативные гарантии, является ограничивающим фрактором, снижающим эфффективность института ЗСЯО и регионального РНЯО. Кроме того, это обстоятельство снижает возможность участникам договора влиять на стороны, не придерживающиеся или подозреваемые в нарушении его положений, как например, в случае с Мьянмой, подозревавшейся в разработке ядерной программы военного назначения [8].

Страны АСЕАН стоят перед необходимостью дальнейшего совершенствования нормативно-правовой базы, регулирующей ядерную сферу, при этом основной целью будет оставаться подписание протокола к Бангкокскому договору, которое, помимо прочего, дает стране-участнице право запроса о проведении миссии по выявлению фактов нарушения договора согласно положению статьи 13 договора [28]. Сотрудничество по продвижению ратификации протокола имеет значение не только для укрепления регионального РНЯО. Пока не ратифицирован протокол, страны ЮВА не могут уделить должного внимания вопросам ФЯБ и экспортного контроля над ядерными материалами.

\section{Заключение}

Ситуация с безъядерной зоной в ЮВА показывает, что международные режимы встроены в более широкие нормативные структуры международного сообщества, и, как следствие, государства не свободны игнорировать институциональные обязательства [29]. Кроме того, концепция "пути АСЕАН", предполагающая избегание конфликтов и уважение суверенитета, предполагает скорее тактику постепенного продвижения к намеченной цели путем долгих переговоров, особенно когда дело касается серьёзных политических вопросов в регионе, где соприкасаются интересы таких гигантов мировой политики, как США, Россия, Китай, Индия.

Проблемы, связанные с созданием ЗСЯО в ЮВА, остаются одним из центральных вопросов в региональной повестке дня ядерного нераспространения наряду с необходимостью преодоления угроз безопасности, связанных с ядерной сферой. От их решения зависит стабильное устойчивое развитие 
государств и экономик ЮВА, являющихся важнейшим хабом региональных и глобальных экономических процессов.

Несомненной заслугой АСЕАН является превращение ЮВА в территорию, где отсутствуют крупномасштабные боевые действия. В то же время это оказалось возможным во многом благодаря тому, что страны ЮВА выработали формат взаимозависимой безопасности, неразрывной друг от друга и как часть общей безопасности региона, что демонстрирует понимание АСЕАНовскими лидерами высокой степени ответственности в сорерах, где высока цена ошибки. В стремлении действовать согласовано в решении острых вопросов они продолжают работать с МАГАТЭ, которая, выступая координационным центром проведения политических дискуссий, предоставляет странам ЮВА возможности для расширения международного сотрудничества в области ЯБ. Ядерный фрактор продолжает сохранять значение в углублении международного сотрудничества стран ЮВА с ведущими государствами в данной сфрере, прежде всего, с Россией, которая, обладая значительным стратегическим потенциалом и качественными разработками, смогла сохранить высокую репутацию в укрепления ЯБ и зарекомендовать себя гарантом мирного использования атомной энергии под контролем МАГАТЭ.

\section{Литература}

1. Ахтамзян И.А. Бангкокский договор [Электронный ресурс]. URL: http:// pircenter.org/sections/view/section_id/31 (дата обращения: 28.06.2020).

2. Ахтамзян И.А. Зона, свободная от ядерного оружия [Электронный ресурс]. URL: http://pircenter.org/sections/view/section_id/100 (дата обращения: 30.06.2020)

3. Ключанская С.А. Основные направления развития ядерной энергетики стран Ассоциации государств Юго-Восточной Азии в конце XX начале XXI века// Вестник Томского университета. 2010. N 333. С. 7173.

4. Колбин А. Создание ЗСЯО в Юго-Восточной Азии: почему ядерной пятеркой до сих пор не подписан протокол к Бангкокскому договору?// Индекс безопасности. 2013. № 2 (105). Tom 19. C. 85-90.

5. Кутнаева Н.А. Зоны, свободные от ядерного оружия, в структуре международного режима ядерного нераспространения// Известия Уральского федерального университета. Сер. 3. Общественные науки. 2013. № 4 (121). С. 73-89.

6. Поправка к Конвенщии о фризической защите ядерного материала// Информационный циркуляр МАГАТЭ [Электронный ресурc]. URL: https://www.iaea.org/sites/ default/files/infcirc274r1m1_rus.pdf (дата обращения: 30.06.2020).

7. Чебан А. Физическая безопасность в Юго-Восточной Азии: чем может помочь Россия// Индекс безопасности. 2014. № 2 (108). Том 20. С. 66-82.

8. Albright D., Walrond C. Technical Note: Revisiting Bomb Reactors in Burma and an Alleged Burmese Nuclear Weapons Program// ISIS Report. 2011. April 11// [Электронный pecypc]. URL: https://isis-online.org/uploads/isis-reports/documents/Burma Analysis_Bomb_Reactors_11April2011.pdf (дата обращения: 16.07.2020).

9. ASEANTOM, Provisional Agenda of the 6th Annual Meeting of the ASEAN Network of Regulatory Bodies on Atomic Energy (ASEANTOM) and Technical Session on Nuclear Security in ASEAN. - Krabi, Thailand (2019). Office of Atom for Peace/l [Электронный ресурc]. URL: https://www.oap.go.th/en/news/3743-session-on-nuclear6th-annualmeeting-of-aseantom-and-technical-security-in-asean (дата обращения: 19.06.2020).

10. ASEANTOM, RAS9077 Supporting Regional Nuclear Emergency Preparedness and Responsein ASEANRegion(2019)//[Электронныйресурc]. URL: http://122.155.190.95/ aseantom5/index.php/2018/07/30/on-going-project4/ (дата обращения: 13.07.2020).

11. Chamberlain T. L., Dickerson S., Ravenhill S. D., Murray A., Morris F.A., Herdes G.A. Regional Radiological Security Partnership in Southeast Asia - Increasing the Sustainability of Security Systems at the Site-Level by Using a Model Facility Approach. Conference: Proceedings of the 50th Annual Meeting of the Institute of Nuclear and Materials Management. United States: N.-Y., 2009// [Электронный ресypc]//URL: https:// www.osti.gov/biblio/990572-regional-radiological-security-partnership-southeastasiaincreasing-sustainability-security-systems-site-level-using-model-facility-approach (дата обращения: 16.07.2020). $29 \mathrm{p}$

12. CNS Global Incidents and Trafficking Database. Annual Report 2017. July 2018.

13. Dhaka, Moscow satisfied with progress of Rooppur Nuclear Power plant// Dhaka Tribune. -March 3, 2019 [Электронный pecypc]. URL: https://www.dhakatribune. com/ bangladesh/event/2019/03/10/dhaka-moscow-satisfied-with-progress-of-rooppurnuclearpower-plant (дата обращения: 30.06.2020). 
14. Emmert D. Southeast Asia: Nuclear Terrorism and Proliferation Concerns// Federal.com. November 30, 2019 [Электронный pecypc].URL: https://www.e3federal. com/southeast-asia-nuclear-terrorism-and-proliferation-concerns (дата обращения: 20.07.2020).

15. Finch R. International Cooperation in Nuclear Forensics: Southeast Asia// CSCAP Nuclear Energy Experts Group Meeting Da Lat, Vietnam 11-12 November 2013 [Электронный ресурс]. URL: http://csis.org/files/attachments/131111_Session\%202_Finch.pdf (дата обращения: 19.07.2020).

16. Mely C.-A., Trajano J.C. Nuclear governance in the Indo/Asia-Pacific: Building out from Southeast Asia?// International Conference on Nuclear Security (ICONS 2020). S. Rajaratnam School of International Studies, Nanyang Technological University. Singapore, 2020. 10-14 February. 17 p.

17. Murogov V.M. Critical notes: history, state, problems and prospects of nuclear science and technology// Nuclear Energy and Technology. 2019. N 5. Pp. 241-248.

18. Murogov V.M. Nuclear Technology: History, State and Technical Challenges of Nuclear Power Development. Responsible Science Program ISTC, 2019. 123 p.

19. Nuclear Security Culture. Implementing Guide. International Atomic Energy Agency. - Vienna, 2008. 40 p.

20. Nuclear-Weapon-FreeZones// [Электронный pecypc]. URL: http://www.un.org/ en/ events/nuclearweaponelimination/pdf/7-International-Day-for-the-Total-EliminationofNuclear-Weapons-Nuclear-Weapon-Free-Zones.pdf (дата обращения: 12.07.2020).

21. Outline History of Nuclear Energy [Электронный ресурc]. URL: https://www. world-nuclear.org/information-library/current-and-future-generation/outline-historyofnuclear-energy.aspx (дата обращения: 12.08.2020).

22. Prospects for nuclear security partnership in Southeast Asia Prepared by the James Martin Center for Nonproliferation Studies (CNS, Monterey, United States), the Center for Energy and Security Studies (CENESS, Moscow, Russia), and the Vienna Center for Disarmament and Non-Proliferation (VCDNP, Vienna, Austria). MonterreyMoscowVienna. May 2012. 72 p.

23. Protocol to The Treaty on Southeast Asia Nuclear Weapon-Free Zone [Электронный ресурс]. URL: http://disarmament.un.org/treaties/t/bangkok_protocol/text (дата обращения: 12.07.2020).

24. Rizki S.BATAN Beberkan Penerapan Sistem Keamanan Nuklir di Indonesia// Acurat.co. 2020. 3 Maret. [Электронный pecypc]. URL: https://akurat.co/iptek/id1030792read-batan-beberkan-penerapan-sistem-keamanan-nuklir-di-indonesia (дата обращения: 26.07.2020).

25. Statistik Lingkungan Hidup Indonesia (Environment Statistics of Indonesia), 2017. 270 p.

26. Sustaining and Strengthening Efforts - Statements. International Conference on Nuclear Security. - 10-14 February 2020. - Vienna, Austria [Электронный ресурc]. URL: https://www.iaea.org/events/nuclear-security-conference-2020/statements (дата обращения: 17.07 .2020 ).

27. The Disaster Riskscape Across Asia-Pacific: Pathways for resilience, inclusion and empowerment. - Asia-Pacific Disaster Report, 2019. 130 p.

28. Treaty on the Southeast Asia Nuclear Weapon-Free Zone [Электронный ресурс]. URL: http://disarmament.un.org/treaties/t/bangkok/text (дата обращения: 12.07.2020)

29. Viotti P. R., Kauppi M.V. International Relations Theory. 5th edition. Pearson. 2011. $496 \mathrm{p}$.

30. Zone of Peace, Freedom and Neutrality Declaration 1971 [Электронный ресурс]. URL: http://www.mfa.go.th/asean/contents/files/other-20130527-163245-351392.pdf (дата обращения: 12.07.2020).

\section{Транслитерация по ГОСТ 7.79-2000 система Б}

1. Akhtamzyan I.A. Bangkokskij dogovor [EHlektronnyj resurs]. URL: http:// pircenter.org/sections/view/section_id/31 (data obrashheniya: 28.06.2020).

2. Akhtamzyan I.A. Zona, svobodnaya ot yadernogo oruzhiya [EHlektronnyj resurs]. URL: http://pircenter.org/sections/view/section_id/100 (data obrashheniya: 30.06.2020)

3. Klyuchanskaya S.A. Osnovnye napravleniya razvitiya yadernoj ehnergetiki stran Assotsiatsii gosudarstv YUgo-Vostochnoj Azii v kontse KHKH nachale KHKHI veka/l Vestnik Tomskogo universiteta. 2010. N 333. S. 7173.

4. Kolbin A. Sozdanie ZSYAO v YUgo-Vostochnoj Azii: pochemu yadernoj pyaterkoj do sikh por ne podpisan protokol k Bangkokskomu dogovoru?// Indeks bezopasnosti. 2013. № 2 (105). Tom 19. S. 85-90.

5. Kutnaeva N.A. Zony, svobodnye ot yadernogo oruzhiya, v strukture mezhdunarodnogo rezhima yadernogo nerasprostraneniya// Izvestiya Ural'skogo federal'nogo universiteta. Ser. 3. Obshhestvennye nauki. 2013. № 4 (121). S. 73-89. 
6. Popravka $\mathrm{k}$ Konventsii o fizicheskoj zashhite yadernogo materiala// Informatsionnyj tsirkulyar MAGATEH [EHlektronnyj resurs]. URL: https://www.iaea.org/sites/ default/files/infcirc274r1m1_rus.pdf (data obrashheniya: 30.06.2020).

7. CHeban A. Fizicheskaya bezopasnost' v YUgo-Vostochnoj Azii: chem mozhet pomoch' Rossiya// Indeks bezopasnosti. 2014. № 2 (108). Tom 20. S. 66-82.

8. Albright D., Walrond C. Technical Note: Revisiting Bomb Reactors in Burma and an Alleged Burmese Nuclear Weapons Program// ISIS Report. 2011. April 11// [EHlektronnyj resurs]. URL: https://isis-online.org/uploads/isis-reports/documents/Burma_Analysis_ Bomb_Reactors_11April2011.pdf (data obrashheniya: 16.07.2020).

9. ASEANTOM, Provisional Agenda of the 6th Annual Meeting of the ASEAN Network of Regulatory Bodies on Atomic Energy (ASEANTOM) and Technical Session on Nuclear Security in ASEAN. - Krabi, Thailand (2019). Office of Atom for Peace// [EHlektronnyj resurs]. URL: https://www.oap.go.th/en/news/3743-session-on-nuclear-6th-annualmeeting-of-aseantom-and-technical-security-in-asean (data obrashheniya: 19.06.2020).

10. ASEANTOM, RAS9077 Supporting Regional Nuclear Emergency Preparedness and Responsein ASEANRegion(2019)//[EHlektronnyjresurs]. URL: http://122.155.190.95/ aseantom5/index.php/2018/07/30/on-going-project4/ (data obrashheniya: 13.07.2020).

11. Chamberlain T. L., Dickerson S., Ravenhill S. D., Murray A., Morris F.A., Herdes G.A. Regional Radiological Security Partnership in Southeast Asia - Increasing the Sustainability of Security Systems at the Site-Level by Using a Model Facility Approach. Conference: Proceedings of the 50th Annual Meeting of the Institute of Nuclear and Materials Management. United States: N.-Y., 2009// [EHlektronnyj resurs]//URL: https:// www. osti.gov/biblio/990572-regional-radiological-security-partnership-southeast-asiaincreasing-sustainability-security-systems-site-level-using-model-facility-approach (data obrashheniya: 16.07.2020). 29 p.

12. CNS Global Incidents and Trafficking Database. Annual Report 2017. July 2018.

13. Dhaka, Moscow satisfied with progress of Rooppur Nuclear Power plant// Dhaka Tribune. -March 3, 2019 [EHlektronnyj resurs]. URL: https://www.dhakatribune.com/ bangladesh/event/2019/03/10/dhaka-moscow-satisfied-with-progress-of-rooppur-nuclearpower-plant (data obrashheniya: 30.06.2020).

14. Emmert D. Southeast Asia: Nuclear Terrorism and Proliferation Concerns// Federal.com. November 30, 2019 [EHlektronnyj resurs].URL: https://www.e3federal. com/southeast-asia-nuclear-terrorism-and-proliferation-concerns (data obrashheniya: 20.07.2020).

15. Finch R. International Cooperation in Nuclear Forensics: Southeast Asia// CSCAP Nuclear Energy Experts Group Meeting Da Lat, Vietnam 11-12 November 2013 [EH]ektronnyj resurs]. URL: http://csis.org/files/attachments/131111_Session\%202_Finch.pdf (data obrashheniya: 19.07.2020).

16. Mely C.-A., Trajano J.C. Nuclear governance in the Indo/Asia-Pacific: Building out from Southeast Asia?// International Conference on Nuclear Security (ICONS 2020). S. Rajaratnam School of International Studies, Nanyang Technological University. Singapore, 2020. 10-14 February. 17 p.

17. Murogov V.M. Critical notes: history, state, problems and prospects of nuclear science and technology// Nuclear Energy and Technology. 2019. N 5. Pp. 241-248.

18. Murogov V.M. Nuclear Technology: History, State and Technical Challenges of Nuclear Power Development. Responsible Science Program ISTC, 2019. 123 p.

19. Nuclear Security Culture. Implementing Guide. International Atomic Energy Agency. - Vienna, 2008. 40 p.

20. Nuclear-Weapon-Free Zones// [EHlektronnyj resurs]. URL: http://www.un.org/ en/events/nuclearweaponelimination/pdf/7-International-Day-for-the-Total-Eliminationof-Nuclear-Weapons-Nuclear-Weapon-Free-Zones.pdf (data obrashheniya: 12.07.2020).

21. Outline History of Nuclear Energy [EHlektronnyj resurs]. URL: https://www. world-nuclear.org/information-library/current-and-future-generation/outline-history-ofnuclear-energy.aspx (data obrashheniya: 12.08.2020).

22. Prospects for nuclear security partnership in Southeast Asia Prepared by the James Martin Center for Nonproliferation Studies (CNS, Monterey, United States), the Center for Energy and Security Studies (CENESS, Moscow, Russia), and the Vienna Center for Disarmament and Non-Proliferation (VCDNP, Vienna, Austria). MonterreyMoscow-Vienna. May 2012. 72 p.

23. Protocol to The Treaty on Southeast Asia Nuclear Weapon-Free Zone [EHlektronnyj resurs]. URL: http://disarmament.un.org/treaties/t/bangkok_protocol/text (data obrashheniya: 12.07.2020).

24. Rizki S.BATAN Beberkan Penerapan Sistem Keamanan Nuklir di Indonesia// Acurat.co. 2020. 3 Maret. [EHlektronnyj resurs]. URL: https://akurat.co/iptek/ id-1030792read-batan-beberkan-penerapan-sistem-keamanan-nuklir-di-indonesia (data obrashheniya: 26.07.2020).

25. Statistik Lingkungan Hidup Indonesia (Environment Statistics of Indonesia), 2017. 270 p. 
26. Sustaining and Strengthening Efforts - Statements. International Conference on Nuclear Security. - 10-14 February 2020. - Vienna, Austria [EHlektronnyj resurs]. URL: https://www.iaea.org/events/nuclear-security-conference-2020/statements (data obrashheniya: 17.07.2020).

27. The Disaster Riskscape Across Asia-Pacific: Pathways for resilience, inclusion and empowerment. - Asia-Pacific Disaster Report, 2019. 130 p.

28. Treaty on the Southeast Asia Nuclear Weapon-Free Zone [EHlektronnyj resurs]. URL: http://disarmament.un.org/treaties/t/bangkok/text (data obrashheniya: 12.07.2020)

29. Viotti P. R., Kauppi M.V. International Relations Theory. 5th edition. Pearson. 2011. $496 \mathrm{p}$.

30. Zone of Peace, Freedom and Neutrality Declaration 1971 [EHlektronnyj resurs]. URL: http://www.mfa.go.th/asean/contents/files/other-20130527-163245-351392.pdf (data obrashheniya: 12.07.2020).

Золотухин И. Н., Бобыло А. М. Ядерная безопасность в Юго-Восточной Азии: вызовы и направления сотрудничества.

Статья посвящена изучению ядерного фактора в ЮВА в контексте измерения региональной безопасности. В работе фригурирует анализ основных вызовов ядерной безопасности в ЮВА, создающих препятствия в реализации национальных программ атомной энергетики, а также проблемы обеспечения физической ядерной безопасности. Отдельное внимание уделено формированию безъядерной зоны в ЮВА (ЗСЯО), оформленной в рамках Бангкокского договора 1995 г. и причин, не позволяющих ЗСЯО в ЮВА окончательно превратиться в устойчивый региональный механизм решения вопросов ядерной безопасности. Методической основой работы является анализ результатов исследований зарубежных и отечественных авторов, а также материалов, документов по исследуемой теме.

Ключевые слова: Юго-Восточная Азия, АСЕАН, сотрудничество, безопасность, ядерная безопасность, атолная энергетика, МАГАТЭ

Zolotukhin I. N., Bobylo A. M. Nuclear Security in Southeast Asia: Challenges and Areas of Cooperation.

The article highlights the issues of nuclear security in Southeast Asia focusing on the regional aspects of the prospect for peaceful nuclearization. The paper analyzes the main challenges to nuclear safety and security in Southeast Asia which create the obstacles of the implementation of national nuclear energy programs as well as the problems of ensuring physical nuclear security. Particular attention is paid to the formation of a nuclear-free zone in Southeast Asia (NWFZ), formalized in the framework of the Bangkok Treaty of 1995. The reasons preventing NWFZ in Southeast Asia from finally becoming a stable regional mechanism for resolving nuclear safety issues are clarified in the work. The article is based on the analysis of the results of the Russian and foreign researchers as well as the data and documents on focused problem.

Key words: Southeast Asia, ASEAN, cooperation, security, nuclear energy, nuclear energy, IAEA

Для цитирования: Золотухин И. Н., Бобыло А. М. Ядерная безопасность в Юго-Восточной Азии: вызовы и направления сотрудничества // Ойкумена. Регионоведческие исследования. 2020. № 4. C. 137-147. DOI: 10.24866/1998-6785/2020-4/137-147

For citation: Zolotukhin I. N., Bobylo A. M. Nuclear Security in Southeast Asia: Challenges and Areas of Cooperation // Ojkumena. Regional researches. 2020. № 1. P. 137-147. DOI: $10.24866 / 1998-6785 / 2020-4 / 137-147$ 